\title{
All Hands on Deck in Curriculum and Instructional Processes
}

\author{
Gena D. Lewis ${ }^{1, *}$, Kathleen F. Liace $^{2} \&$ Patricia A. Braun ${ }^{2}$ \\ ${ }^{1}$ College of Graduate Studies in Literacy and ECE, Concordia University Chicago, USA \\ ${ }^{2}$ College of Education and Health Services, Benedictine University, Lisle, USA \\ *Correspondence: College of Graduate Studies in Literacy and ECE, Concordia University Chicago, USA. E-mail: \\ Gena.Lewis@cuchicago.edu
}

Received: September 17, $2019 \quad$ Accepted: October 8, $2019 \quad$ Online Published: October 25, 2019

doi:10.5430/wje.v9n5p83 URL: https://doi.org/10.5430/wje.v9n5p83

\begin{abstract}
Teachers present their perceptions when designing and mapping curriculum to implement standards-based instruction and assessment. It appears that teachers are willing but not always able to make curriculum and instructional decisions. Participation of teachers varies from district to district. When curriculum is given to teachers as part of their district curriculum team or committee efforts, all are not part of the process. Teachers are not given a space to deeply engage and create clarity of the content within the curriculum. Teachers are not provided the time, guidance, platform or power to gather the necessary information and make the necessary decisions. No wonder there are misguided practices when it comes to curriculum and instruction. The data collected from our study led the research team to create a model for the process of designing and implementing standards-based instruction and assessment.
\end{abstract}

Keywords: curriculum, instruction, teachers, process, design, standards-based instruction, assessment

\section{Introduction}

Teachers and specialists spend significant amounts of time trying to plan and organize curriculum and instruction that meet learning standards and student needs. Teachers are involved in the process of curriculum development as content experts and also in their daily instruction. This expertise is imperative for the design of effective curriculum and instruction. This process for curriculum design and instruction looks different based on the state, current process of curriculum and materials implementation, and common practices within the district in response to curriculum and instruction. Many schools have reported buying and or "borrowing" a pre-written curriculum and then using that in their daily lesson plans or directly using textbooks as lesson plans and or guides for instruction (Kane et al., 2016; Jacobs, 2004; Wiggins et al., 1998). This is not part of the curriculum and instruction process and is not best practice (Jacobs, 2004; Wiggins et al., 1998). This article introduces three major research-based recommendations for curriculum and instruction:

- All teachers must be involved in ongoing curriculum and instruction processes

- Close reading and or deep learning must be enacted as part of curriculum and instruction

- Clarity of curriculum and instruction is vital so that all users will become content experts.

Currently, in the field of education, teachers are being asked to design and implement standards-based instruction and assessment and fulfill teacher evaluation matched to this criterion. The lack of direction in this area is evident and many teachers and districts are left to wonder how to accomplish this task. If this publication can offer guidance to the field based on asking teachers across the state what they are doing to fulfill this obligation then this work will be able to assist in gaining a bird's eye view of the current field. This research intends to guide those schools in their mission to promote teacher behaviors that use research supported curriculum design and best practice to plan instruction. The field needs to provide research driven strategies and ideas for implementing curriculum and instruction that use standards. Steiner (2017) states that "Curriculum is a critical factor in student academic success." Comprehensive, content-rich curriculum is a common feature of academically high-performing countries." The cumulative impact of high-quality curriculum can be significant and matters most to achievement." The overarching 
conclusions from Slavin, Lake, Davis \& Madden (2011) are that “curriculum is deeply important, that a teacher's or district's choice of curriculum can substantially impact student learning, and that - as a result- the paucity of evidence upon which sound instructional, purchasing, and policy decisions can be made is a matter of deep concern and urgent need."

\subsection{The Research Question}

The research team noted that many students in the master's of education programs where they teach, demonstrated different conceptions and misunderstood practices when it came to curriculum design and instructional planning. Many did not see the difference between designing curriculum and planning instruction. Some felt that curriculum and instruction were the same while others stated that they did not know the process of curriculum development in their school. The research team decided to analyze the involvement and perceived process schools in Illinois use when developing curriculum and instruction. This confusion and misunderstanding of the definitions and process became the impetus for the research study. The question for our research therefore became, what are teachers' involvement when designing and mapping curriculum and planning instruction to implement standards (Appendix B) within K-6 schools?

\section{Literature Review}

\subsection{Introduction}

The use of the word curriculum needs to be clearly developed so that the history and current practices are clear. Designing a curriculum requires ongoing communication and collaboration among teachers and administrators in order to ensure the curriculum is attainable, consistent, accountable, and sustainable. Designing curriculum and instruction requires clearly written objectives birthed from learning standards. Objectives need to be matched with a clear assessment objective to help clearly detail how the standards are to be assessed. Then the materials and methods can be chosen and made clear through lesson planning. Curriculum maps were for many years given as a way to clearly detail how all of these pieces of the curriculum and instruction puzzle would be scoped and sequenced and then implemented. Curriculum mapping is a process used for collecting data about the actual curriculum taught by teachers, versus referring to intended curriculum guides. Fenwick English (1980), an early curriculum map developer, noted that most curriculum maps included two components: "content taught and time spent to teach the curriculum." (p. 558). English maintained that congruence between the real curriculum and the written curriculum could be achieved by using the results of curriculum maps to show "what is actually taught, how long it is being taught, and the match between what is being taught and the district's testing program" (p. 559).

While curriculum maps were originally used by school districts as a tool to audit curriculum, they eventually evolved into tools many districts use for aligning standards and assessment practices (Shilling, 2013). Currently, many school districts employ a curriculum mapping procedure of collecting key curriculum data including content, processes and skills, and assessments, primarily based on the work of Heidi Hayes Jacobs (1997). Jacobs developed a curriculum mapping procedure for collecting curriculum data organized around the school calendar, to provide both a vertical (grade-to-grade) and horizontal (across courses in a grade) perspective, for "creating a 'big picture' for curriculum decision making" (Jacobs, p. 61).

Curriculum maps provide a framework for examining the vertical and the horizontal planning of implementing curriculum, which helps educators avoid making separate curriculum decisions. A framework such as this encourages several research-based practices: communication and collaboration; reflective inquiry; shared purpose and; student learning. According to Susan Udelhofen, (2005), each of these practices "influence school improvement and are deeply embedded in the curriculum mapping process and outcomes" (p. 3).

When teachers have the opportunity to engage in active dialogue with their colleagues about their teaching practices and curriculum, not only do they strengthen their professional communication and collaboration with one another, they also deepen their understanding about students' learning within the school/district. The focus of the communication centers on improving students' learning experience by analyzing instructional practices and assessments. According to Rick DuFour's and Robert Eaker's research on effective schools (1998), "Collaborative processes not only result in better decisions but also foster a sense of community that is an integral part of school improvement" (p. 220).

Curriculum mapping lends itself to reflective inquiry by encouraging teachers to look at one another's maps and discuss their findings. Revisions made to the curriculum are based on shared information with the final goal of improving student learning. 
Examining curriculum maps allows teachers to gain insights regarding one another's teaching philosophies, values and visions. The more actively involved teachers are in the mapping process, the better informed decisions they can make regarding students' learning. (Kallick \& Colosimo, 2009).

Susan Udelhofen clearly summarizes curriculum mapping in her book, Keys to Curriculum Mapping: Strategies and Tools to Make it Work (2005):

Curriculum mapping is an alternative that provides a process-oriented model that is respectful of the knowledge of every teacher, encourages collaboration and reflection, and is sensitive to the complexities of student learning and the teaching profession. It offers the flexibility to address the changing curriculum needs of school districts by relying on the active participation and expertise of teachers. It is a process that consists of procedures that include easy curriculum modifications, revisions, and updates on a timely basis, resulting in a current, reality based, standards-aligned curriculum. (p. 3)

Three important areas essential to curriculum design are the involvement of all teachers in the writing and planning of curriculum and instruction, deep learning of the content within those standards and clarity of curriculum design and instruction. These three areas are the core of the research based recommendations in the study and must be enacted as part of curriculum and instruction.

\subsection{Involvement of All Teachers}

The first area is the change in perspective from the traditional small group or committee representation in curriculum and instruction to the use of the entire teaching community to support the work of curriculum and instruction. The research of Handler (2010) and Alsubaie (2016) support the finding of using all teachers as curriculum leaders in schools. This would require a change in thinking and implementation as it would call for all teachers to be involved in curriculum and instructional design. Carl states (2009) the involvement of academic staff is critical to any change in organizational curriculum design processes. This is not only because they put the new approaches into practice, but also because engagement is better when faculty have a sense of control and choice in the outcomes (Huizinga et al. 2014). This reflection and shared understanding required to engage in curriculum design will help to bring teachers together as a community of practice. Teachers play an important role as key agents of curriculum change, and can contribute to the successful and dynamic development of curriculum if they are empowered with the appropriate skills and knowledge. Huizinga (2014) shares that teachers' own disposition towards curriculum can also be an empowering aspect adding value to the process of relevant curriculum development.

\subsection{Close Reading}

The next area in the literature review is that of close reading. Close reading is important to curriculum and instruction because it is vital to know the curriculum you are teaching at a very deep level to become an expert at the myriad of instructional tools and techniques for pedagogical variation within the art of teaching. It is important to see the act of close reading and its impact on curriculum and shared expertise of teachers using the curriculum. Curriculum and instruction are separate but dependent operations in the same process (Hale, 2017). Curriculum planning is a long process. It is a two-step system of designing curriculum and implementing instruction. Curriculum is the theory, philosophy and vision of the standards, including the act of writing of curriculum maps. The other part is instruction. Instruction is the process of creating lessons with strong design and assessments and choosing materials and methods to teach the curriculum well. Green (2007) identified some common problems teachers encounter when they attempt to implement curriculum and instruction when they do not fully understand the process: the most vital of which is "failure to clearly define what students are expected to learn" (pp. 15-16).

\subsection{Clarity}

Clarity in curriculum and instruction is linked to greater gains and impact on instruction by several studies (Fendick, 1990; Hattie, 2016; William, 2016). The meta-analysis of Hattie (2016) focuses on what studies say about the way to effectively design instruction. One thing he states is that the use of clear objectives and focused teaching will impact quality instruction. Hattie's meta-analysis shows the strong effect size of instructional clarity in delivery. William's work supports Hattie's focus on clarity of instruction and use of clear objectives. The use of the standards to add clarity to the instructional lesson plan will be a great place to implement mandated curriculum using clarity of purpose and then best practices in instruction. Fendick (1990) states that clarity and objective setting make instruction more strongly correlated to student achievement. The better the clarity, the more impactful the instruction. Clarity in the research of Fendick, is stated as "Clarity of organization, Clarity of explanation, Clarity of examples and guided practice and Clarity of assessment of student learning" (p. 16). Fendick's research states 
The teacher must give structure to the lesson. She or he does this by (a) stating objectives and relating them to the course objectives, (b) clearly relating the teaching to the objectives, and (c) reviewing what has been covered in the lesson (pp. 23).

Also the research of Dylan William (2016) states that, "Clarifying, sharing, and understanding learning intentions and criteria for success, getting the students to really understand what their classroom experience will be and how their success will be measured" (p. 24). This is very important to instructional effectiveness. William's work supports Hattie's focus on clarity of instruction and use of clear objectives. The use of the standards to add clarity to the instructional lesson plan will be a great place to implement mandated curriculum using clarity of purpose and then best practices in instruction. Hattie, (2009), suggests that well-designed curriculum and well-planned instruction moves students from their current level of competency toward explicit criteria for success. The instructional design with clear instructional objectives makes a difference in student achievement. Teacher clarity is near the top of that list, with an effect size of 0.75 . Teacher clarity turns out to be vital to achieving many other influences at the top rungs of Hattie's list. Clarity can help achieve shared vision by writing and understanding a well written curriculum and clear guidelines for instruction within a district. Without a curriculum structure, there is chaos"(Squires, 2014, pp. 7).

\section{Methods}

Our question, "What are teachers' involvement when designing and mapping curriculum to implement curriculum and instruction?" led us to design questions in our survey that explored teacher involvement and actions in the curriculum and instruction process. The questions' active language ensured that the responses focused on behaviors. The survey included data on relevant characteristics and source of participants in the survey questionnaire, but assured that no identifying features were revealed through the specific details. Surveys are best used when they are intended to describe current practices or behaviors, understand attitudes and or evaluate the outcomes of an initiative which were all pertinent to our research questions. Our research intended to uncover the involvement of teachers in planning and organizing for their instructional day, much of which is done at home and or in the hours prior and post to their school day. To collect this data the researchers would not be able to use observational data in the school setting as this would not be the time or place that this part of the practice takes place. To get at the practices and behaviors of teachers many things would be hidden or unintended practices and those would be harder to unearth if not given freedom to use short answer and extended response methods so we needed to include methods for allowing teachers to give longer and less restricted responses. In the article by ARS (April, 2017), the authors report that there is growing agreement that survey research is facing issues and challenges. A recent committee commissioned by the National Science Foundation concluded that "survey research is at a crossroads. The need for information to track the public's behaviors, experiences, needs, and preferences has risen dramatically in recent years, at the same time, the challenges of conducting high quality surveys are substantial" (Krosnick et al., 2015, p. 18). Sample matching (Couper, 2017) describes an approach used to achieve representative samples in internet survey data collection models. Rather than adjusting to population totals after the fact, this approach matches respondents from a large nonprobability sample (e.g., an access panel) to respondents from a large probability sample (such as the American Community Survey or the Current Population Survey, using a set of auxiliary variables available in both. The matched cases in the nonprobability sample are then invited to complete the Web survey. Thus, sample balance is aimed for at the recruitment phase. As with other model-based approaches, the success of this method depends on the variables used in the models. Nonresponse to the Web survey invitation may further erode representativeness. (9) Surveys are important in educational research because they can provide quantitative descriptions of the characteristics, behaviors, and attitudes of students, teachers, principals, parents, district leaders, and other specific populations so that decisions can be made that match research foundation. Accurate data from a well-designed survey can be instrumental in guiding effective policy and practice recommendations.

\subsection{Study}

A questionnaire was sent electronically to 580 K-6 teachers, administrators and specialists randomly selected from a list of Illinois urban, rural and suburban school districts using a database for random sampling. The survey sought to clarify thoughts about curriculum design and instructional practices. One hundred and sixteen educators responded to the survey. The questions were in open-ended format or forced choice. Responses to the survey questions were analyzed and encoded to discover patterns of participants' responses regarding involvement in designing curriculum and planning instruction. 


\subsection{Questionnaires}

Questionnaires are the most commonly used tool in survey research. The results of this survey are written with focus on research based methodology and survey tenets of design. The questionnaire produced valid and reliable demographic variable measures and yielded valid and reliable individual disparities by using self-report scales.

\subsection{Selection of Study Participants}

The research team sent out an electronic survey to Illinois K-6 urban, suburban, and rural schools districts and counties that were randomly selected using a survey selection tool. From the National Center for the Statistics of Public Education in 2013, (Aud et al., 2013), the Illinois public school system (prekindergarten through grade 12) operates within districts governed by locally elected school boards and superintendents. In 2013 Illinois had $2,072,880$ students enrolled in a total of 4,266 schools in 1,070 school districts which is roughly one teacher for every 15 students, compared to the national average of $1: 16$. There was roughly one administrator for every 278 students, compared to the national average of one administrator for every 295 students. The data Figure below shows the number of each grade level that responded in the survey. This will inform the reader as to how many in the sample size were from each grade.

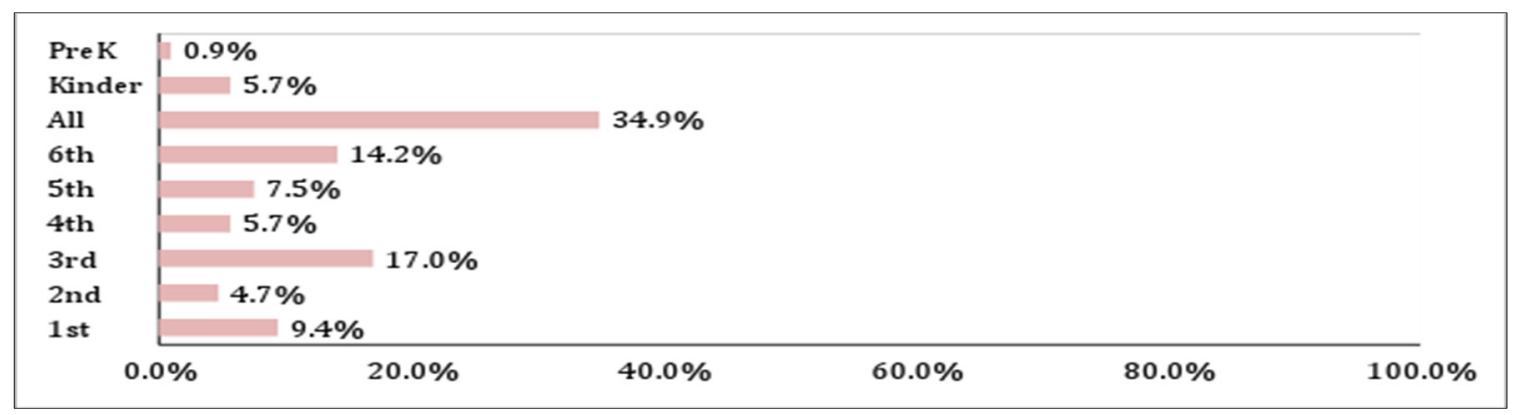

Figure 1. Percentage of Teachers in Each Grade

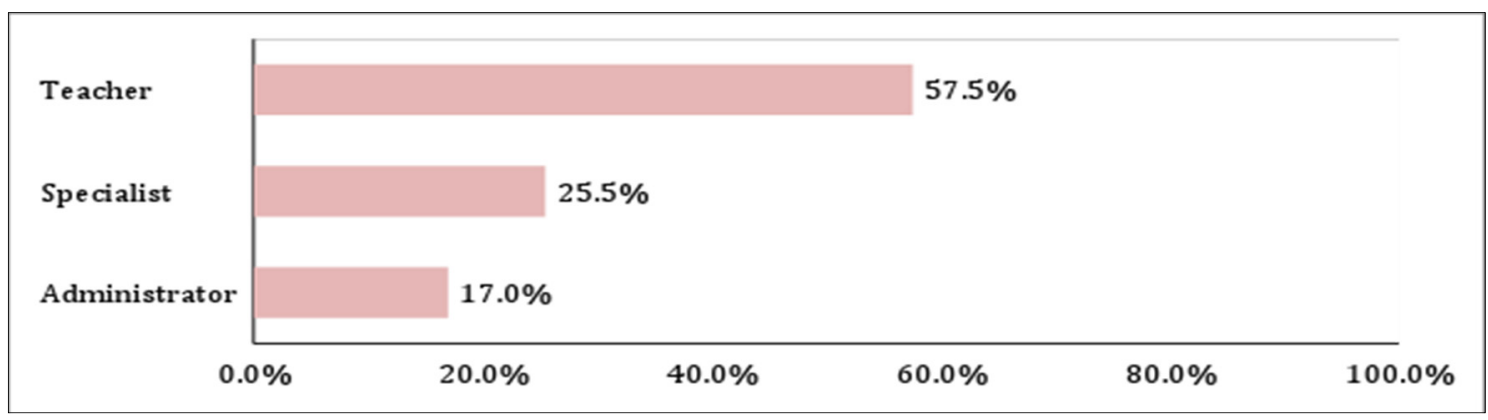

Figure 2. Percentage of Educator Roles in the Study Survey

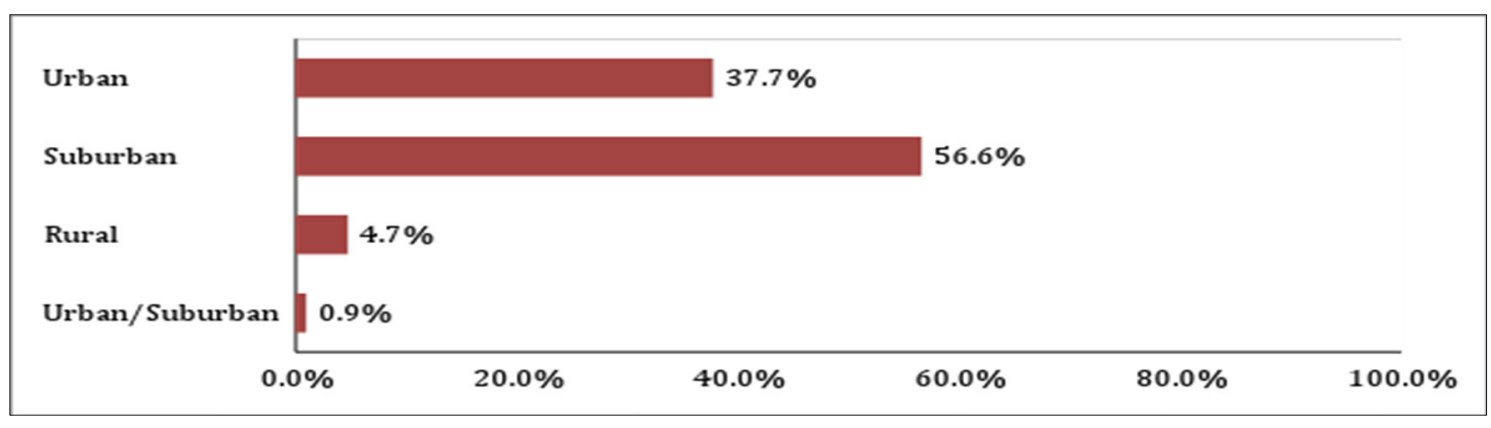

Figure 3. Type of School Demographic in Survey 
In the above Figures the demographic setting for the study is revealed. Figure 1 identifies the percent of teachers at each grade level that responded in the randomized survey. Figure 2 identifies the specific roles that the respondents have within the school setting. The distribution of staff in Figure 2 very closely mimics the numbers of staff in Illinois Public schools based on the Illinois school report card. This helps to give authenticity to the data set. Figure 3 depicts Illinois region types responding to the survey. It was important in the survey email submissions that the Gmail submissions be evenly distributed to urban, suburban and rural region types in Illinois.

\subsection{Anonymity}

To guard the anonymity of participants, no identifying information was collected and participants' responses will remain confidential as only members of the research team will have access to information gathered from the surveys. Participants will only identify their professional role in the school (Special Education teacher; English Language Learner teacher; Third grade teacher) and the school setting in which they teach (Rural, Urban, or Suburban).

\section{Results}

\subsection{The Study Questions and Findings}

\subsubsection{Question 1}

Of the 10 Illinois State standards sets which of the following are you currently employing in our school district? (Please check those that apply.)

Figure 4 demonstrates that schools in our study are using state standards sets mandated in the state of Illinois. However, it is clear that a high percentage of schools are using the English Language Arts Learning Standards but are not fully implementing the other standards sets.

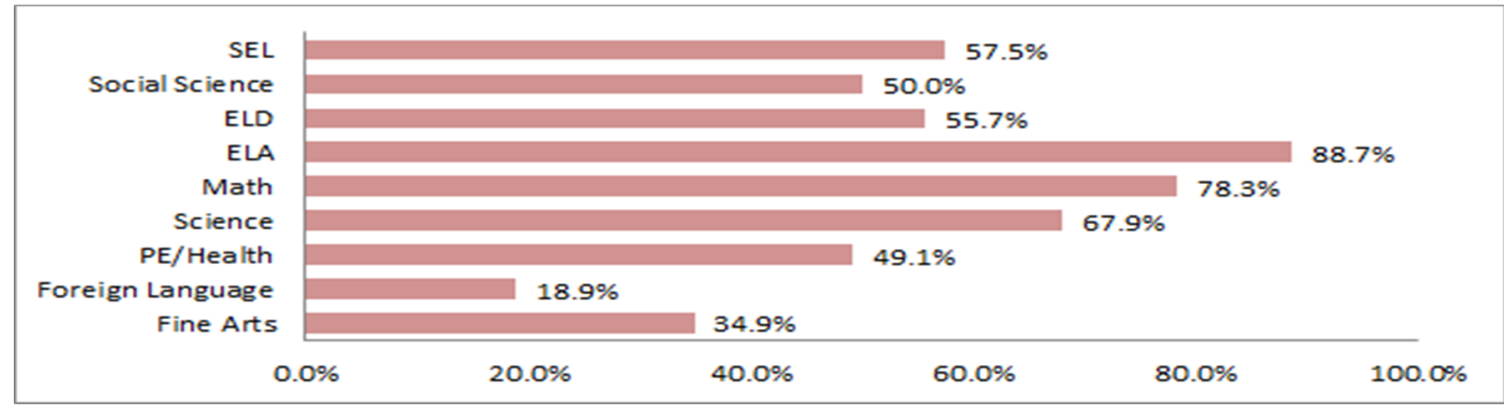

Figure 4. Number and Percentage of Standards Being Implemented in Illinois

\subsubsection{Question 2}

Do teachers have an active role in your school in designing/planning instruction?

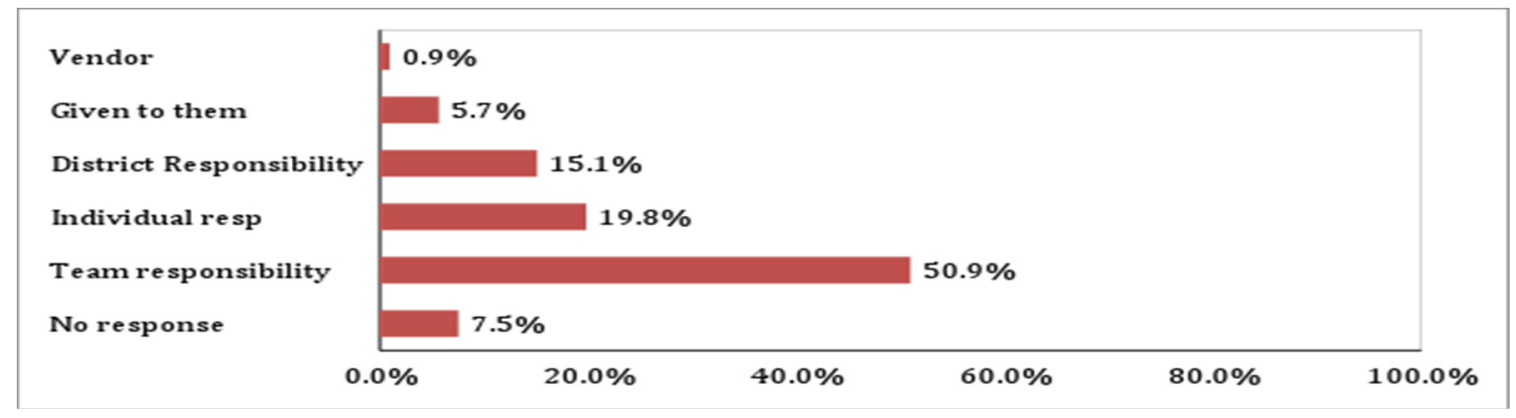

Figure 5. Number and Percentage of Teachers' Active Role in Designing/Planning Instruction 
Of the 106 study participants, 88 respondents (83\%) replied that they have an active role in their schools in planning instruction. This is a substantial number of teachers involved in designing instruction. Though, when asked the follow-up question, why or why not? (Whose responsibility is designing instruction in your school?), half of the respondents $(50.9 \%)$ replied that it is a team responsibility, while $(19.8 \%)$ of the respondents replied it is an individual responsibility. Collectively, based on the two responses, (70.7\%) of the participants have an active role in designing instruction.

\subsubsection{Question 3}

Do teachers have an active role in your school in creating assessments? Why or why not?

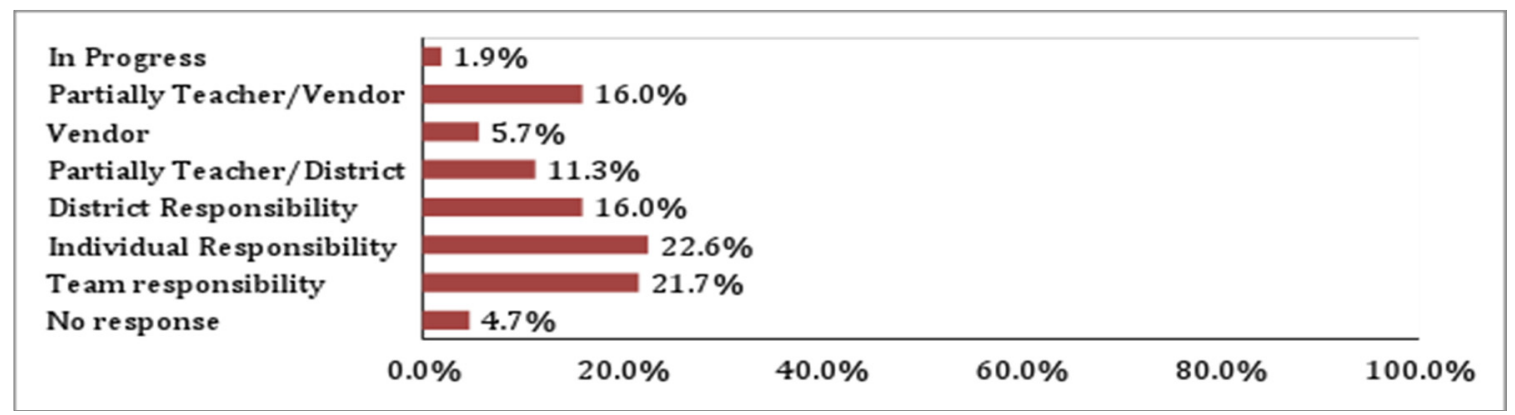

Figure 6. Number and Percentage of Teachers' Active Role in Creating Assessments

When asked why or why not teachers have an active role in creating assessments in their schools, (Who creates assessments in your school?) the two most common responses were: individual responsibility $(22.6 \%)$ and team responsibility $(21.7 \%)$, for a collective total of $(44.3 \%)$. The next most common responses were district responsibility $(16.0 \%)$, which tied with partially teacher and partially vendor $(16.0 \%)$. The next strongest response was partially teacher and partially district (11.3\%). Looking at the responses we can see that the teacher involved responses (all answers except for vendor, in progress and no response) still yet, combine to only a little over half at $55.6 \%$. This level is not acceptable if we are to maintain best practices in curriculum and instruction.

\subsubsection{Question 4}

What resources do you use to align and implement curriculum and instruction?

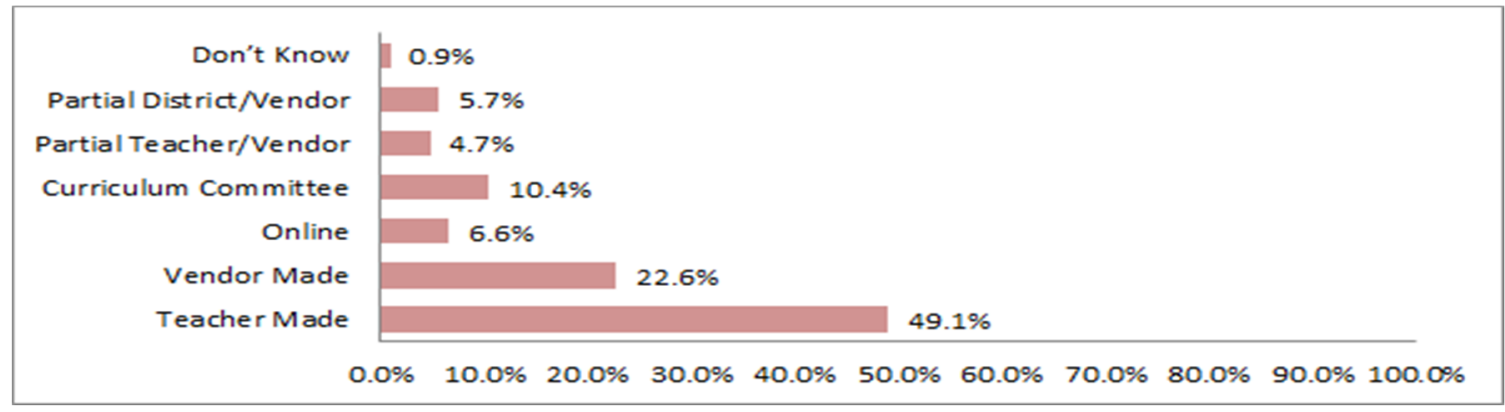

Figure 7. Resources Used to Align and Implement Curriculum and Instruction

In the survey responses for question 4 the largest number of respondents identified teacher made resources as the most common resources used in schools in Illinois. This requires teachers to make the materials themselves to get exactly what they need for the help students master the standards.

\subsubsection{Question 5}

How would you best use curriculum committee time if you were given the role of planning a curriculum day at your school? 


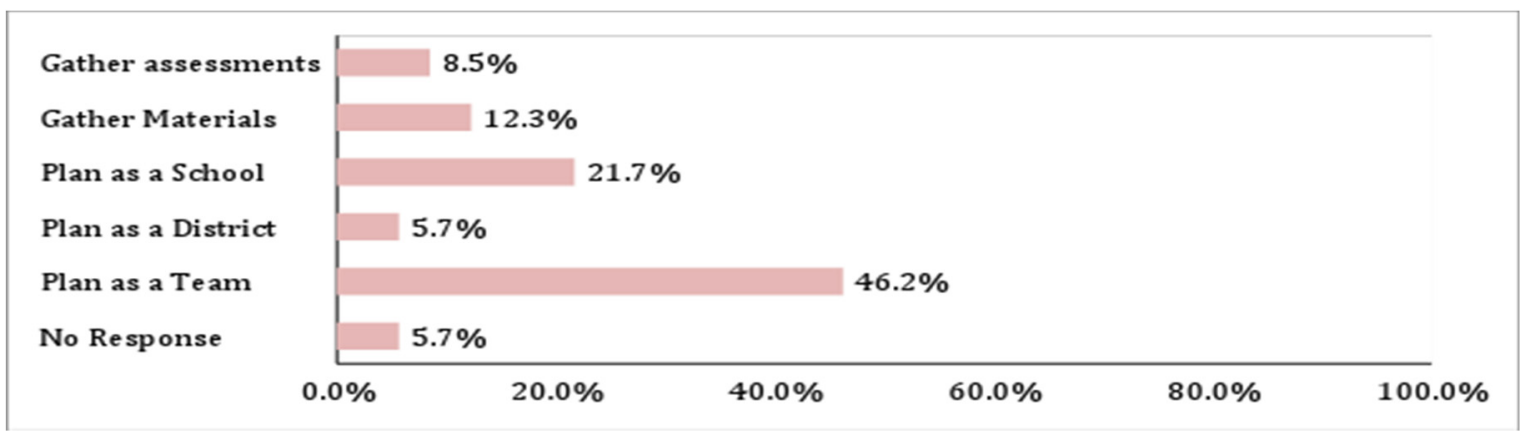

Figure 8. Number and Percentage of Teachers' Use of Curriculum Committee Time

The Figure above shows that teachers desire time to plan with their grade level teams and to acquire more access to content understanding. Data in the chart above indicate that a great number of respondents desired time to plan as a school. This is representative of curriculum and instruction and helps move teachers toward cross grade and cross team planning, understanding and awareness. This practice helps to make visible any curriculum gaps and all redundancies and or inconsistencies in the curriculum. It also serves to enforce a school wide advancement of academic achievement (Marzano, 2014).

Also, the data reveals that as the size of the planning group grows the desire to plan in this manner diminishes. This leads us to understand that teachers seek to plan in smaller groups and, when doing so, impact instruction in more focused planning sessions.

\subsubsection{Question 6}

What process does your school follow for curriculum and instruction?

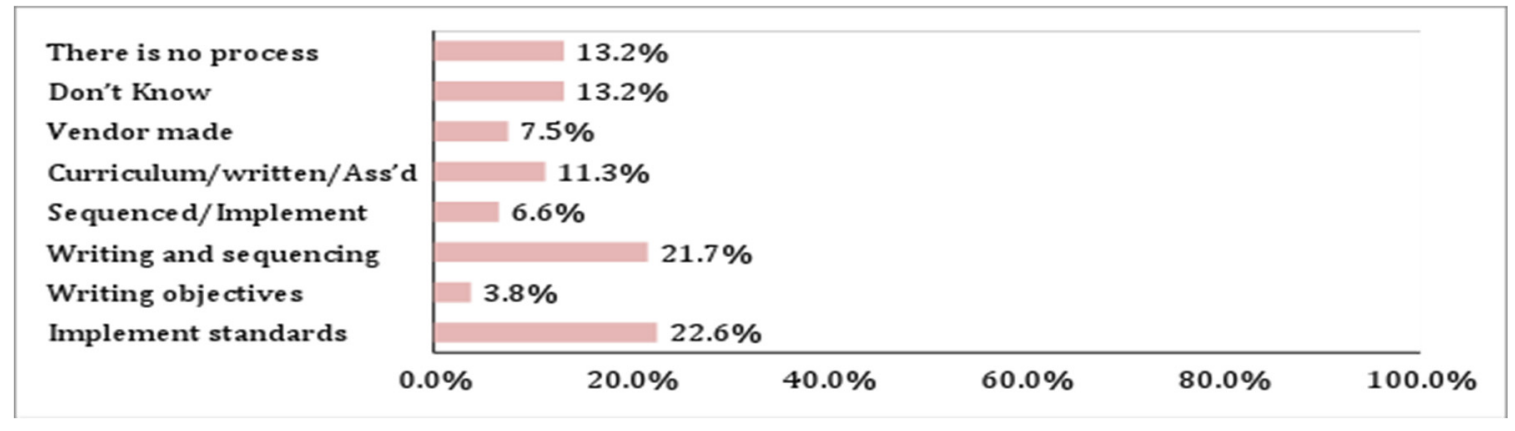

Figure 9. Number and Percentage of Teachers' Curriculum and Instruction Process

The responses in Figure 9 demonstrate that teachers are lacking in direction for a process of curriculum and instruction. This supports the notion that in the area of planning and organizing instruction, teachers and districts are at a loss due to the many responses in congruence with not having a curriculum process. According to Green (2007), the process of instruction using standards involves six steps: Teachers must be clear (themselves) about what they expect their students to know and be able to do by the end of a specific unit or lesson. Teachers need to tell their students what they expect them to now and be able to do. Teachers need to teach students the knowledge and skills needed to show mastery. Teachers need to check (assess) to see if the students have learned what the teachers expected them to. Teachers need to report to the students whether or not they have mastered content and to what degree of mastery. Teachers need to re-teach as needed and whenever appropriate (pp. 14-15).

4.1.7 Question 7 Does your school create its own curriculum map or does it adapt other schools, districts, states or vendors? 


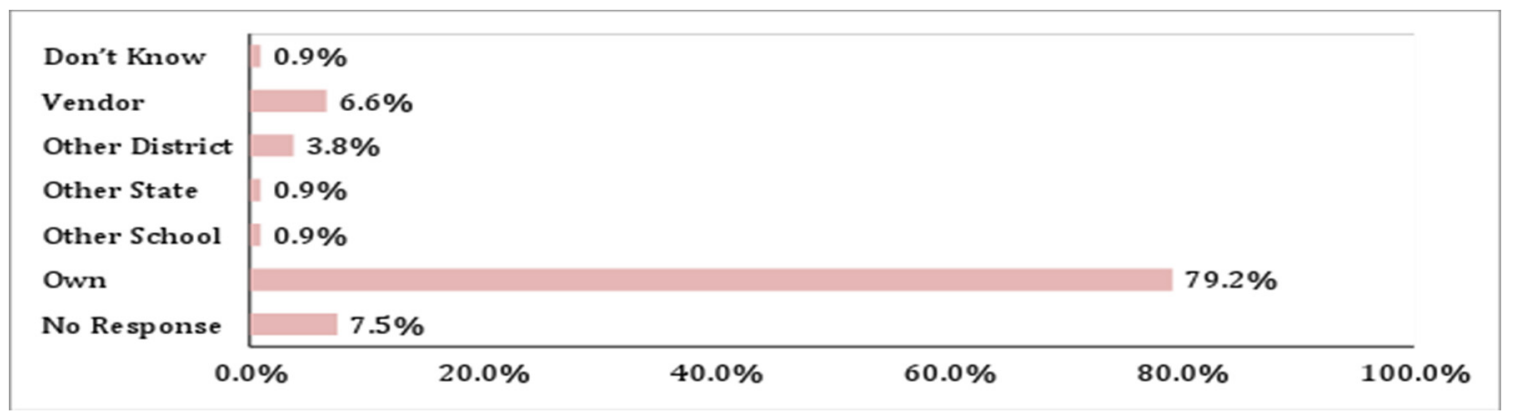

Figure 10. Number and Percentage of Schools That Create Their Own Curriculum Map

Nearly $80 \%$ of the respondents replied that their school creates its own curriculum map. This overwhelming response is very unclear in the explanations that follow as many name a vendor product as the origination for their curriculum and also other school districts and states. This curriculum development process encourages communication, collaboration, reflection, negotiation, and a shared professional purpose. Additionally, as DuFour and Eaker (1998) noted, "Collaborative processes foster a sense of community that is an integral part of school improvement" (p. 220).

\subsubsection{Question 8}

What should happen after curriculum maps have been created to further support implementation and student learning?

\begin{tabular}{|c|c|c|c|c|c|}
\hline \multirow{9}{*}{$\begin{array}{l}\text { Team Monitoring } 7 \\
\text { Self Monitoring } 6 \\
\text { Realignment \& Expansion } 5 \\
\text { Analyze assessments } 4 \\
\text { Assess resources } 3 \\
\text { Re-evaluate periodically } 2 \\
\text { Re-evaluate annually } 1 \\
\text { No Response }\end{array}$} & \multicolumn{5}{|c|}{$23.7 \%$} \\
\hline & \multicolumn{5}{|l|}{$2.2 \%$} \\
\hline & \multicolumn{5}{|l|}{$5.4 \%$} \\
\hline & \multicolumn{5}{|l|}{$5.4 \%$} \\
\hline & \multicolumn{5}{|l|}{$8.6 \%$} \\
\hline & & 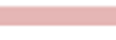 & $4 \%$ & & \\
\hline & \multicolumn{5}{|l|}{$4.3 \%$} \\
\hline & \multicolumn{5}{|l|}{$2.2 \%$} \\
\hline & $20.0 \%$ & $40.0 \%$ & $60.0 \%$ & $80.0 \%$ & $100.0 \%$ \\
\hline
\end{tabular}

Figure 11. Number and Percentage of Teachers' Opinion about Next Steps

The data in Figure 11 reveals that almost half of the educators surveyed felt that periodic re-evaluation is fundamental to the process of curriculum mapping. Many teachers also felt that monitoring should be part of the process of curriculum mapping. This was surprising as the research team was not expecting this answer in the open ended responses. A quarter of those surveyed felt that monitoring needed to be a part of the process of curriculum mapping. Many noted the absence and lack of assessments and or assessment guidance. Also many felt that dissemination was not needed as part of the process of designing curriculum. This may be due to the fact that it is not a part of the process that is working well or that it lacks a level of simplicity. Technology will be a great tool for solving many of these issues.

\subsubsection{Question 9}

Check all of the following that apply in the process of curriculum design and instruction based on what you define as necessary steps in the process. 


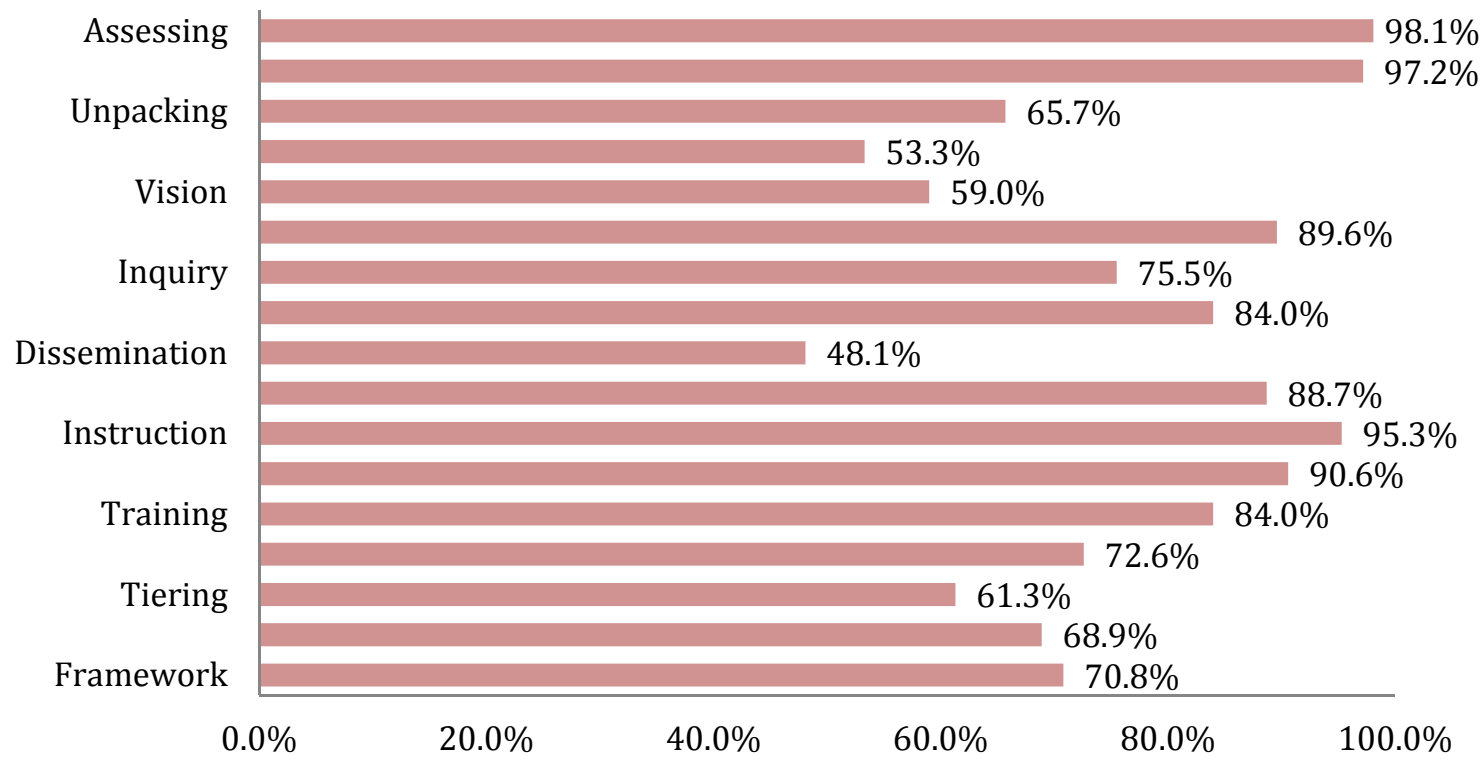

Figure 12. Participants' Identified Steps in the Process of Curriculum Design and Instruction

The final question in the survey leads us to understand that the processes of curriculum design and instruction are varied and multifaceted. The research team used 9 studies to frequency rate the most prevalent terms in the studies that report best practices in curriculum design and instruction. There were 9 studies used by many educational researchers; Heidi Hayes Jacobs, Robert Marzano, David Steiner, Janet Hale, Thomas Kane, Carol Ann Tomlinson and Grant Wiggins. This lack of consistent terms and steps in the curriculum process have been mirrored in the researchers' masters courses for many years. In discussions with our master's level students in the graduate program, the team has been consistently perplexed by the inconsistency of definitions used and also the comments that schools are no longer writing objectives, or required to make lesson plans as they need to just follow textbooks. The aspects of writing objectives from the standards is seemingly seen as an unnecessary task if you can just teach the standards using a few items gathered. In Figure 12 we notice that the areas of assessing, planning, instructing, implementing and revising are all at high levels of choice in the areas for curriculum design and instruction. Due to these misconceptions and misunderstood terms the researchers created a visual (Appendix E) to clarify each step and term within the curriculum and instruction process. The terms are hierarchical in nature and display a clear set of stages that match those in the Hale (2008) and Jacobs (2004) work.

\subsection{Study Results and Recommendations}

The study was conducted to analyze the responses of teachers involved in creating curriculum and instruction. Three specific findings explain the basis for the misunderstandings.

\subsubsection{Involvement}

All Teachers are not fully involved in creating instruction and assessments. All teachers, not just committee members, need to be involved in the entire curriculum and instruction process. As seen in the findings of the survey there was an inconsistency in the participation of teachers in the writing and or creating of curriculum and assessment. The research team recommends exterminating committees so everyone will experience the process of reading, evaluating and analyzing the standards and then writing them into objectives for a curriculum. Hale (2008) states that curriculum is an ongoing process and that it should not end once it is first implemented.

\subsubsection{Deep Learning}

Schools do not follow a consistent process for deep learning of standards for the purpose of understanding and clarity. Hale $(2008,2017)$ suggests curriculum mapping takes a great depth of knowledge of the content and deep understanding of the curriculum to be able to fully implement. In order to implement curriculum mapping, teachers must overcome a vast learning curve. Schools need to give time to understand the 10 sets of content standards prior to writing curriculum and or lesson planning. 


\subsubsection{Clarity}

Clear and consistent objectives and curriculum planning helps to eliminate the confusion seen in the study question responses. To achieve what they want in the classroom, teachers need clarity. Also a clear scope and sequencing should be evident, so that the teacher will teach the range of related skills and the order in which they should be learned built from a developmental learning model. Teacher clarity is near the top of that list, with an effect size of 0.75 - far and away more influential on learning than such factors as class size (0.21), type of school (0.24) or the use of digital tools (0.32). Just as important, teacher clarity turns out to be vital to achieving many other influences at the top rungs of Hattie's list. This research team recommends finding ways to facilitate time for this planning to take place. The need for large spans of time to do this task is so important. Districts could use the first few days prior to school start, to come together for deep learning of the standards and key terms, mapping and planning. Teachers can be given time to fully experience all content within their grade and or near their grade to write complete and connected student learning objectives. This is such important work that it is imperative to allot the time.

\subsubsection{Process}

There must be a process for Curriculum and Instruction - In the study it becomes clear that the teachers and specialists are asking for clarification of their role as well as a research based process for curriculum and instruction.

\subsection{Elaboration for the Steps in the Process}

From deep learning, clarity and full involvement come four easy applications for fully visiting the curriculum and instruction steps and or processes in each district. To help enact each of the 3 applications a planning sheet has been developed for each step to make these clear for schools. The following tools will guide the process.

Tools in Appendix D - F include the following:

- Curriculum, Assessment and Instruction Processes

- Curriculum Design Stages

- Planning template

\subsubsection{Elaboration of all Steps}

Use the All Involved Protocol (Appendix B) to start the conversation about involving all faculty and staff in the process. The involvement of every teacher may be a hard sell, as traditionally a curriculum committee, (a small selected group of experts), have researched, designed, and distributed the curriculum to teachers. Also in the past, it has been difficult to find time to gather all teachers together. This step is imperative and essential for true curriculum understanding and implementation, and must be incorporated in the curriculum and instruction process. No alternative to these steps can achieve the level of needed involvement. All faculty and staff will not become part of the deep learning and will continue to be excluded from building and understanding curriculum design if the small curriculum committee design continues to be used.

\subsubsection{Tool for Step 1}

The All Involved Protocol is a list of action items that invites all teachers to the table and secures multiple content expertise and active participation. Not only is it important to include all instructional agents in the process, but it is also imperative to commit time for the curriculum process meetings to take place. Large windows of time will be needed to develop, revise or revisit curriculum and these designated times will most likely be outside of the school year or at the annual institute days.

To start at step one, schools need to examine the Curriculum Design Steps Visual (Appendix D) and view each of the areas individually. It is important that all involved share philosophy and theory; agree on the structure, framework and model of curriculum; understand the standards; engage in curriculum designing; and work together to write lessons, choose materials, create plans and agree on assessments.

This visual will help schools begin a conversation surrounding all of the major components of each step. From there, all members in the school will need to create a school glossary for the steps in the process. This will help to maintain shared understanding and alleviate misguided practices.

\subsection{Curriculum Design Stages}

There are curriculum design stages necessary to consider in completing the curriculum design and planning instruction. (Appendix E) Planning, articulating and developing, implementing and evaluating are the basic steps. But revisiting, revising and reviewing are necessary as the process of curriculum design and instructional planning is 
ongoing. In these five steps the process of curriculum design is made clear with all necessary components listed so that schools will not neglect to include all of the steps needed.

\subsection{Tool for Step 3}

All teachers will be given substantial time for creating instructional curriculum units ICUs, vocabulary lists, and anchor charts for each unit and a set of definitions that are clear for each grade level and unit segment in the curriculum so that all teachers will have a close reading and deep understanding of the content in their units of instruction. This will eliminate misunderstandings and help build a shared understanding that allow for depth of knowledge and high level application activities filled with discussion and technology that involve students in inquiry worth their time and connected to assessment and objectives. There needs to be a method to help teachers close read their grade level standards and curriculum document so they become the experts and fully understand all for the content they are to plan throughout the year. The Close Curriculum Reading Protocol was designed to give steps to a process of close reading the curriculum. (See Appendix C).

\subsection{Tool for Step 4}

Step 4 is a step that helps to provide clear and simple planning. In this step the appendix provides a clear and simple template (Appendix E) for planning instruction that includes pertinent elements of a thorough plan for instruction. This template lists the following areas to include in the plans:

- ICU or Instructional Curriculum Unit Questions for each Instructional Curriculum Unit that addresses one or two Learning Objectives taken from the curriculum map.

- $\quad$ ELL Language Objectives and Scaffolds that assure strong learning for diverse student populations.

- SPED Scaffolds/Accommodations \& Modifications for students of varying abilities.

- Assessment/Evaluation that will monitor progress.

- Engagement and Technology Strategies and Tools to enhance learning.

- Instructional Procedures/ Learning Tasks (outlined) to guide instruction

- Resources and Materials to support the diverse learning levels of all students.

\section{Conclusion}

It is imperative that educators and administrators come together with all hands on deck to collaboratively design curriculum and plan instruction. This research study gives clear support for thoughtful curriculum work which must be done with all teachers in the school to improve curriculum and instruction. It supports the use of clarity in practices and a clear process with all steps fully enacted by all members. Finally the practice of deep learning through close reading of the standards and definitions of key terms will fully immerse teachers as content experts so that they can better understand how to differentiate the content. Changing the status quo and rethinking how schools are operationalizing a true process of curriculum and instruction is so important for the future of schools. This will help to clear up the many misunderstandings of terms and steps of curriculum design. Many schools see the materials (textbooks) as important in the process of curriculum and instruction. If schools use the intended process, this is the final and least important step. Many times schools do this first. Curriculum and instruction is more about knowledge and understanding of content through thoughtful planning rather than the items in the classroom. This and many other misunderstood practices will be alleviated if we do the four steps mentioned above. Clear and deeply understood curriculum and instruction that is well-designed will provide a clear, thoughtful education for students that will enable them to achieve academic success. Therefore, a new definition of curriculum and instruction should emerge. The important aspects must include the following: involving all members of a school as experts in their content, clarifying as a product of shared understanding, and gaining a deep knowledge through designing and planning using a process to design curriculum and plan instruction that is brought about by all hands on deck.

\section{References}

Alsubai, M. A. (2016). Curriculum Development: Teacher Involvement in Curriculum Development. Journal of Education and Practice, 7(9), 106-107. Retrieved from https://files.eric.ed.gov/fulltext/EJ1095725.pdf

Aud, S., Wilkinson-Flicker, S., Kristapovich, P., Rathbun, A., Wang, X., \& Zhang, J. (2013). The Condition of Education 2013 (NCES 2013-037). U.S. Department of Education, National Center for Education Statistics. Washington,

DC.
Retrieved

from 
https://search-ebscohost-com.libweb.ben.edu/login.aspx?direct=true \&db=eric\&AN=ED542714\&site=ehost-live \&scope $=$ site

Carl, A. (2009). Teacher empowerment through curriculum development theory into practice. Juta \& Company. Retrieved from http://cucproxy.cuchicago.edu/login?url=http://search.ebscohost.com/login.aspx?direct=true\&AuthType=cookie ,ip,cpid\&custid $=$ s8419239\&db=a9h\&AN=9711211033\&site $=$ ehost-live

Couper, M. (2017). New Developments in Survey Data Collection, Annual Review of Sociology, 145(43), 121-145. https://doi.org/10.1146/annurev-soc-060116-053613

DuFour, R., \& Eaker, R. (1998). Professional Learning Communities at Work: Best Practices for Enhancing Student Achievement. Bloomington, National Educational Service. Received from http://cucproxy.cuchicago.edu/login?url=http://search.ebscohost.com/login.aspx?direct=true\&AuthType=cookie ,ip, cpid\&custid $=\mathrm{s} 8419239 \& \mathrm{db}=$ eric $\& A N=E D 426472 \&$ site $=$ ehost-live

Fendick, F. (1990). The correlation between teacher clarity of communication and student achievement gain: A meta-analysis. Unpublished doctoral dissertation, University of Florida, Gainesville. Retrieved from https://archive.org/details/correlationbetwe00fend

Green, J. (2007). Standards from start to finish. Leadership, 37(1), 14. Retrieved from https://search-ebscohost-com.libweb.ben.edu/login.aspx?direct=true\&db=a9h\&AN=27366105\&site=ehost-live \&scope $=$ site

Hale, J. (2017). Curriculum Decisions. London: Corwin Press. Retrieved from www.CurriculumDecisions.com

Hale, J. A. (2008). A guide to curriculum mapping: Planning, implementing, and sustaining the process. London: Corwin Press.

Handler, B. (2010) Teacher as Curriculum Leader: A Consideration of the Appropriateness of that Role Assignment to Classroom-Based Practitioners. International Journal of Teacher Leadership, 3(3).

Hattie, J. (2012). Visible Learning for Teachers: Maximizing Impact on Learning. New York, Ny: Routledge.

Huizinga, T., Handelzalts, A., Nieveen, N., \& Vogt, J. M. (2014). Teacher involvement in curriculum design: need for support to enhance teachers' design expertise. Journal of Curriculum Studies, 46(1), 33-57. https://doi-org.libweb.ben.edu/10.1080/00220272.2013.834077

Jacobs, H. H. (2004). Getting results with curriculum mapping. Alexandria, VA: ASCD. Retrieved from https://searchebscohostcom.libweb.ben.edu/login.aspx?direct=true\&db=eric\&AN=ED489051\&site=ehost-live\& scope $=$ site

Kallick, B., \& Colosimo, J. (2009). Using curriculum mapping and assessment data to improve learning. Thousand Oaks, CA: Corwin $\quad$ Press. $\quad$ Retrieved https://search-ebscohost-com.libweb.ben.edu/login.aspx?direct=true\&db=psyh\&AN=2008-12336-000\&site=eh ost-live\&scope $=$ site

Kane, T. J., Owens, A. M., Marinell, W. H., Daniel R. C. Thal \& Staiger, D. O. (2016 February). Teaching HigherEducators' Perspectives on Common Core Implementation. Center for Education Policy Research at Harvard University. Retrieved from http://cepr.harvard.edu/files/cepr/files/teaching-higher-report.pdf.

Marzano, R., \& Scott, D. (2014). Awaken the Learner, Finding the source of Effective Education. Solution Tree Press. Retrieved from https://www.marzanoresources.com/awaken-the-learner

National Governors Association Center for Best Practices. (2010). Common Core State Standards. Retrieved from http://www.corestandards.org/

National Governors Association Center for Best Practices. Council of Chief State School Officers, Washington D.C. Retrieved from http://www.corestandards.org/read-the-standards/

Retrieved

from https://search-ebscohost-com.libweb.ben.edu/login.aspx?direct=true\&db=psyh\&AN=2012-07127-000\&site=eh ost-live\&scope $=$ site

Shilling, T. (2013). Opportunities and Challenges of Curriculum Mapping Implementation in One School Setting: Considerations for School Leaders. Journal of Curriculum and Instruction, 7(2), 20-37. 
https://doi.org/10.3776/joci.2013.v7n2p20-37

Slavin, R. E., Lake, C., Davis, S., \& Madden, N. A. (2011). Effective programs for struggling readers: A best-evidence synthesis. Educational Research Review, 6, 1-26. https://doi.org/10.1016/j.edurev.2010.07.002

Squires, D. A. (2014). Curriculum: District stories of a path to improved achievement. Hauppauge, New York: Nova Science Publishers, Inc.

Steiner, D. (2017). Curriculum Research: What we know and where we want to go. Standards Work. Retrieved from https://standardswork.org/wp-content/uploads/2017/03/sw-curriculum-research-report-fnl.pdf

Udelhofen, S. (2005). Keys to curriculum mapping: Strategies and tools to make it work. Thousand Oaks, CA: Corwin Press. Retrieved from http://us.corwin.com/en-us/nam/keys-to-curriculum-mapping/book226930\#contents

Wiggins, G., \& McTighe, J. (1998). Understanding by Design. Alexandria, VA: ASCD. Retrieved from http://cucproxy.cuchicago.edu/login?url=http://search.ebscohost.com/login.aspx?direct=true\&AuthType=cookie ,ip, cpid\&custid $=$ s $8419239 \& d b=$ nlebk\&AN $=133964 \&$ site $=$ ehost-live

William, D. (2016). Leadership for Teacher Learning: Creating a Culture Where All Teachers Improve So That All Students Succeed. H.B. Ed. Learning Sciences International. Retrieved from http://files.hbe.com.au/samplechapter/LSM8306.pdf

\section{Appendices}

6.1 Appendix A

6.1.1 Survey Questionnaire

Title: Research Questions: What are Teachers' Behaviors When Designing and Mapping Curriculum to Implement Standards-Based Instruction?

Role (i.e. Special Ed, EL, 3rd Grade etc.)

School Setting: Rural Urban Suburban

\subsubsection{Data Collection - Survey}

1. How do you implement standards-based instruction?

2. How would you best use curriculum committee time if you were given the role of planning a curriculum day at your school?

3. What has your school done in the past, present or planned for the future, for standards-based instruction and or curriculum design?

4. What has been done to map curriculum in your school? If nothing has been done, then what should it look like?

5. Do teachers have an active role in your school in designing instruction? Why or why not?

6. Do teachers have an active role in your school in creating assessments? Why or why not?

7. Does your school write its own curriculum or use that of vendors, other schools', districts or states? Why or why not?

8. What should happen after curriculum maps have been created to further support implementation and student learning?

9. Please sequence the following steps in the process of curriculum design and instruction - Please leave out any of the following that you feel are unnecessary or antiquated and or add any that are necessary.

Assessing, Planning, Unpacking, Mission, Vision, Goals, Inquiry, Organization, Dissemination, Implementation, Instruction, Revising, Training, Re-teaching, Tiering, Personalizing, Framework

How do you use standards-based assessment to ensure mastery of standards-based curriculum? 


\subsection{Appendix $B$}

\subsubsection{All Involved Protocol Punch List}

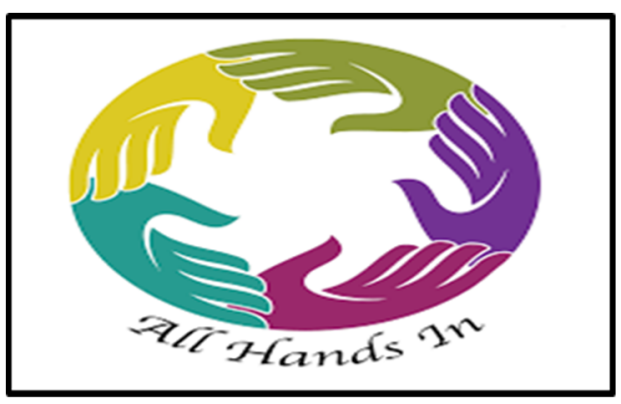

All Involved Protocol Punch list

1. Ask them one on one.

2. Don't always go for pro people first.

3. Make clear what you want people to do.

4. Encourage people to ask questions.

5. Give the big picture, and how each task fits in with the rest - how others work is dependent on them.

6. Start small and build, make tasks manageable

7. HOPE - people need to feel that things can get better.

8. URGENCY - people need to see that time to move is NOW, later or tomorrow will be too late

9. YOU can make a difference!

10. Emotional buy in!

\subsection{Appendix $C$}

Close Curriculum Reading Protocol

6.3.1 First Reading: Start at your grade level and Read the curriculum and do the following tasks:

1. Highlight the nouns in the Student Learning Objectives (SLOs)- define each highlighted noun and give a consensus definition for each noun - you are essentially creating a glossary for shared language and understanding for your grade levels so that you can express the same understanding for your instruction and clear terms for your students.

2. Highlight each verb in the SLO to ensure the level of mastery needed. This will ensure a more consistent language and a clearer assessment.

3. If you curriculum map contains common and or unit assessments then do a crosswalk of the assessment and SLO verbs to ensure that they assess what they are intended to asses. If there are no common or unit assessments then you will need to begin the process of analyzing what assessments you will need to design to assess your SLOs.

4. Pull out a strand of one Spiral/Tiered Activity from the Curriculum - as a team note what additional or extended learning is added at each grade level - discuss how that fully develops the Anchor standard - for example if you use retelling - how does retelling change throughout the map and through each grade level?

5. Create anchor charts and or support units and or materials to fully develop the SLO and assessment.

\subsubsection{Second Reading:}

1. Go through each SLO and list in a quick brainstorm the activities you are doing that help to master the Student Learning Objectives.

2. Eliminate those that do not fully support the objectives. 
3. Add activities that do better at supporting the objectives.

4. Ensure that objectives are not:

1. Large

2. Varied

3. Non-specific

4. Unmeasurable

5. Not action-oriented

6. Targeted to the school needs and population

SLOs need to help be:

1. Small (less is more)

2. Focused - not varied in the content

3. Specific to the task

4. Measurable

5. Action Orientated

6. Targeted using assessment

6.4 Appendix D

\section{Curriculum, Assessment and Instruction Process}

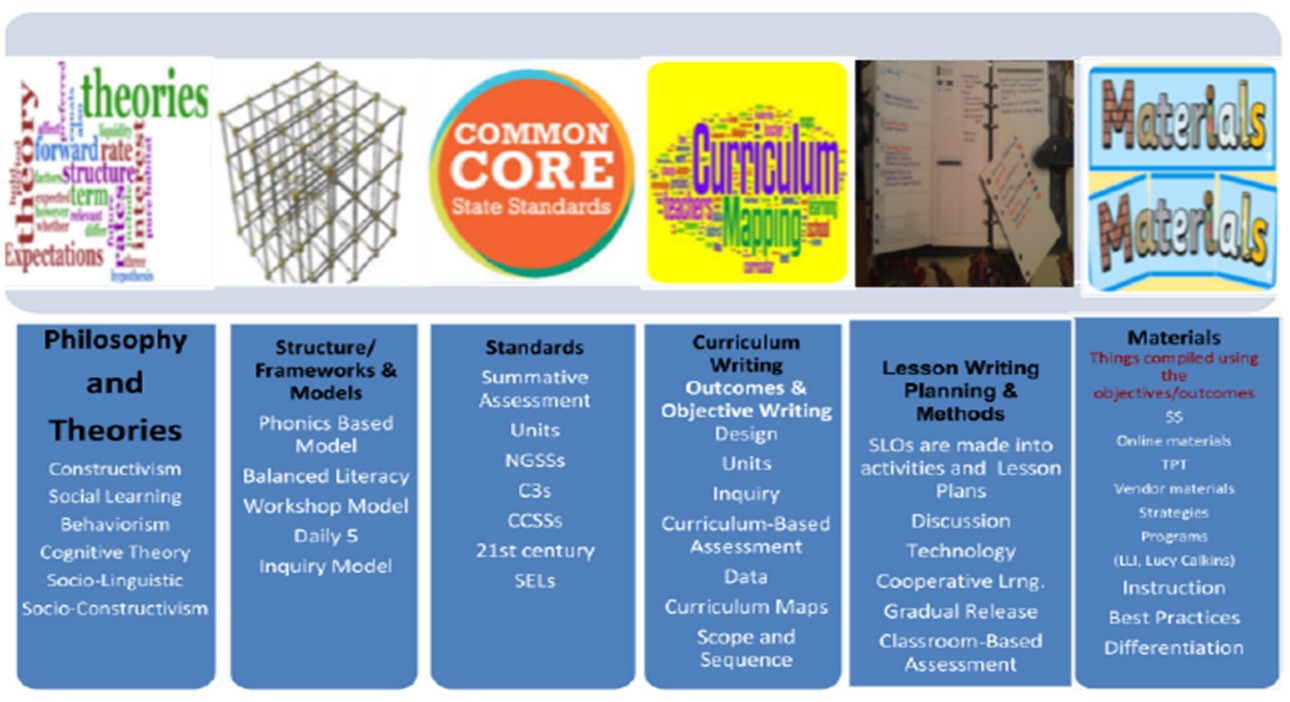

\subsection{Appendix E}

Curriculum Design Stages
A. Planning:

1. Extinguish all curriculum committees - stop all small group curriculum work and enforce whole school $\mathrm{C}$ and $\mathrm{I}$

2. Convening a Curriculum Development Day for all teachers of the school

3. Identifying Key Issues and Trends in the Specific Content Area

4. Assessing Needs and Issues

B. Articulating and Developing:

4. Articulating a K-12 Program Philosophy

5. Defining K-12 Program, Grade-Level and Course Goals 
6. Developing and Sequencing of Grade-Level and Course Objectives

7. Identifying Resource Materials to Assist with Program Implementation

8. Developing and/or Identifying Assessment Items and Instruments to Measure Student Progress

C. Implementing:

9. Putting the New Program into Practice

D. Evaluating:

10. Updating the Program

11. Determining the Success of the Program

E. ReReRe: Revisit, Revise, Review

12. Must be an annual process - ongoing and recursive - never final!

6.6 Appendix $F$

Instruction Planning Tool

\section{Planning Template}

\begin{tabular}{l|l|l}
\hline Unit: & Date \\
\hline $\begin{array}{l}\text { Unit Essential Questions } \\
\text { and Focus }\end{array}$ & \\
\hline Learning Standards & \\
addressed by the SLO & \\
from the map & \\
\hline Learning Objectives taken & \\
from curriculum map - \\
written from the standard \\
above into SLOs \\
\hline $\begin{array}{l}\text { ELL Language Objectives } \\
\text { and Scaffolds }\end{array}$ \\
\hline $\begin{array}{l}\text { SPED } \\
\text { Scaffolds/Accommodation } \\
\text { s \& Modifications }\end{array}$ \\
\hline Assessment/Evaluation & \\
\hline Engagement and & \\
\hline Technology Strategies and \\
Tanlo
\end{tabular}

